\title{
Graft Copolymerization onto Wool Fibers: Graft Copolymerization of Acrylic Acid onto Wool Fibers Initiated by Quinquivalent Vanadium
}

\author{
Gitisudha GIRI, C. N. NANDA, and Rajani K. SAMAL* \\ Macromolecular Research Laboratory, Department of Chemistry, \\ Ravenshaw College, Cuttack-753003, Orissa, India
}

(Received April 11, 1989)

\begin{abstract}
Graft copolymerization of acrylic acid onto wool fibers was carried out with quinquivalent vanadium as the initiator in an aqueous medium under nitrogen atmosphere. The percentage of grafting was influenced by reaction time, temperature, concentrations of acid, monomer, initiator and base polymer. Grafting has also been carried out in the presence of various organic solvents. It has been observed that $193.7 \%$ of grafting is obtained at $55^{\circ} \mathrm{C}$ for $[\mathrm{AA}]=$ $1.46 \mathrm{M},\left[\mathrm{V}^{+5}\right]=0.025 \mathrm{M}, \mathrm{Wool}=0.2 \mathrm{~g}$ and for a reaction time of $6 \mathrm{~h}$. A suitable mechanism has been proposed for graft initiation and termination. A theoretical rate equation has been derived. The behaviour of the graft copolymers towards mineral acids and alkalis has been tested. Their tensile properties, dye-uptake ability and absorption of water and water vapour have also been examined.

KEY WORDS Defatted Wool / Initiator Effect / Monomer Effect / Temperature Effect / Solvent Effect / Tensile Modulus / Dye-Uptake /
\end{abstract}

Wool, a natural protein, called $\alpha$-Keratin has significant characteristics and is used for making warm garments. With a view to enhance the durability of woolen garments and to add improved properties such as better dyeability, prevention of shrinkage and pilling, improved bacterial resistance, hydroscopicity, tensile strength, thermal stability, etc. attempts have been made since 1945 to modify wool fibers chemically. This involves functionality changes via etherification, esterification, urethanation, amidation, etc. ${ }^{1-5}$; by interfacial graft condensation of polyamides, ${ }^{6-8}$ polyurethanes, ${ }^{9}$ polyureas, polyesters, polycarbonates $^{10}$ via radical grafting of vinyl monomers involving high energy radiation. Photochemical and chemical method of initiation involving metal and non-metal ion initiators $^{11-37}$ and through chemical treatments. ${ }^{38-51}$ However, during recent years, chemical methods of initiation of grafting involving metal and non-metal ion oxidisers, organic peroxides, hydroperoxides, aliphatic azo compounds like $\mathrm{Ce}^{+4}, \mathrm{~V}^{+5}, \mathrm{Mn}(\mathrm{IV})$, $\mathrm{Mn}(\mathrm{III}), \mathrm{S}_{2} \mathrm{O}_{8}^{2-}, \mathrm{HSO}_{5}^{-}, \mathrm{H}_{2} \mathrm{O}_{2}, \mathrm{P}_{2} \mathrm{O}_{8}^{2-}$, BPO, CHP, AIBN, etc. have attracted the attention of chemists as has been reviewed by us recently. ${ }^{52}$ Among the chemical initiators quinquivalent $\mathrm{V}(\mathrm{V})$ has a unique identity and it is reported to oxidise a multitude of organic substrates (alcohols, acids, aldehydes, sugars, mercaptanes) in aqueous $\mathrm{H}_{2} \mathrm{SO}_{4}$ medium. ${ }^{53}$ Most of such reaction proceed through a free radical path that effectively initiates vinyl polymerization. Further, quinquivalent vanadium has similar affinity towards macromolecules containing characteristic pendant groups $\left(-\mathrm{OH},-\mathrm{CHO},-\mathrm{NH}_{2},-\mathrm{SH},-\mathrm{COOH}\right.$, etc.) on their backbone so that the interactions of $\mathrm{V}(\mathrm{V})$ with the groups form polymer free radicals

\footnotetext{
* To whom all correspondence should be made.
} 
that initiate grafting, as has been reported by Ikada et al. ${ }^{54}$ in the grafting of MMA onto PVA with V(V).

However, scanty literature is available on the grafting of vinyl monomers onto wool fibers initiated by quinquivalent $\mathrm{V}(\mathrm{V}),{ }^{55-58}$ where graft copolymers show improved thermal stability, dyeability and grafting results in the light fastness of wool fibers. We have therefore been interested in studying graft copolymerization of vinyl monomers onto wool fibers using quinquivalent vanadium $\left(\mathrm{V}^{+5}\right)$ as the initiator so as to improve properties such as high tenacity towards acids and alkalis, improved absorption of water and water vapours, tensile strength, dye uptake ability etc. to the fiber. The present report on grafting of acrylic acid is a part of these studies.

\section{EXPERIMENTAL}

\section{Materials}

Wool fibers were purified by continuous soxhelation in petroleium ether. They were then washed well with warm acetone followed by distilled water and air dried. Acrylic acid (G.S.C) was purified by distillation under reduced. pressure and the middle fraction was collected and used for all experiments. A stock solution of the initiator "V(V)" (0.1 M) was prepared by dissolving $2.925 \mathrm{~g}$ of $\mathrm{NH}_{4} \mathrm{VO}_{3}$ in $5 \mathrm{M} \mathrm{H}_{2} \mathrm{SO}_{4}$ and strength of the stock solution was determined by cerimetry. All other reagents were of B.D.H. (AR) grade and used after purification by standard methods. Graft copolymerization was carried out in a specially designed reaction vessel having outlet and inlet system, for deaeration. The defatted wool fibers $(0.2-1.0 \mathrm{~g})$ were immersed in a mixture containing water and the required amount of acrylic acid. The reaction vessels were deaerated by passing oxygen-free nitrogen for one hour and were then sealed airtight by rubber cappings. The vessels were then kept in a constantly shaking thermostat at the desired temperature, till the mixture attained thermal equilibrium after which the required amount of initiator was injected through the rubber capping and the reaction was carried out for the desired time. The homopolymers were extracted by repeated boiling of the graft copolymers in warm distilled water and methanol till the washings did not yield any precipitate.

From the weight of the graft copolymers and parent fiber the percentage of grafting was calculated as follows.

$$
\text { Percentage of grafting }=((X-Y) / Y) \times 100
$$

where

$X=$ Weight of the graft copolymer

$Y=$ Weight of the original base polymer

\section{Tensile Modulus}

The tensile modulus at the break of the parent fiber and graft copolymers was determined by a "Dutrons" Tensile Tester, Brand-20 kgf capacity, the details of which are cited in the properties section of this manuscript.

\section{Dye-Uptake}

The dye-uptake ability of the grafted samples was assessed using "Sandocryl Golden Yellow B-GRL 300\%" dye and compared with that of the parent fiber.

\section{RESULTS AND DISCUSSION}

Acrylic acid was graft copolymerized with defatted wool fibers initiated by quinquivalent vanadium either alone or in the presence of dil. $\mathrm{H}_{2} \mathrm{SO}_{4}$ under identical reaction conditions. The results of such copolymerizations are presented in Table I. Table I shows that acid $\left(\mathrm{H}_{2} \mathrm{SO}_{4}=0.5 \mathrm{M}\right)$ enhances the percentage of grafting. This enhancement of percentage of grafting may be attributed to increase in the oxidation potential of quinquivalent vanadium due to the production of more active $\mathrm{VO}_{2}^{+}$ species and/or $\mathrm{V}(\mathrm{OH})_{3}^{+2}$. These vanadium spe- 
Table I. Variation in percentage of grafting at different times

Effect of initiators: wool $=0.2 \mathrm{~g} ;[\mathrm{AA}]=1.46 \mathrm{M}$; temp $=$ $50^{\circ} \mathrm{C}$; [nitiator $]=0.01 \mathrm{M}$.

\begin{tabular}{lrrrrrr}
\hline \multirow{1}{*}{ [Initiator] } & \multicolumn{6}{c}{$\%$ Grafting } \\
\cline { 2 - 7 } & $1 \mathrm{~h}$ & $2 \mathrm{~h}$ & $4 \mathrm{~h}$ & $6 \mathrm{~h}$ & $8 \mathrm{~h}$ & $9 \mathrm{~h}$ \\
\hline $\mathrm{V}^{+5}$ & 4.8 & 14.9 & 27.2 & 37.9 & 36.7 & 36.0 \\
$\mathrm{~V}^{+5}$ with $\mathrm{H}_{2} \mathrm{SO}_{4}$ & 10.5 & 17.2 & 30.9 & 54.3 & 53.0 & 53.8 \\
$(0.5 \mathrm{M})$ & & & & & \\
\hline
\end{tabular}

cies have been found potential oxidisers of a large number of organic substrates, whose oxidation proceeds through a free radical path. ${ }^{53}$ In this case, the said vanadium species probably attacks the wool backbone at a faster rate, resulting in the generation of a large number of grafting sites. Further, increase in acid concentration ( $>0.5 \mathrm{M}$ ) still increases the percentage of grafting beyond $53.75 \%$. In this study it was noted that even though increase in acid concentration increases the percentage of grafting to $193.7 \%$, there still exists an optimum concentration of $\mathrm{H}_{2} \mathrm{SO}_{4}(0.75 \mathrm{M})$ and other reaction components $\left(\left[\mathrm{V}^{+5}\right]=0.015 \mathrm{M}\right.$, $[\mathrm{AA}]=1.46 \mathrm{M}$, temp $=45^{\circ} \mathrm{C}$ ) at which the graft copolymer (with $46.2 \%$ grafting) having ideal properties is obtained, beyond which deterioration in the grafted samples is observed. This might be due to oxidative and hydrolytic chain cleavage of the polypeptide chain in wool backbone at higher concentrations of $\mathrm{V}^{+5}, \mathrm{H}_{2} \mathrm{SO}_{4}$ and reaction temperature beyond $45^{\circ} \mathrm{C}$.

\section{i) Effects of Monomer/Polymer Ratios}

The effects of the monomer/polymer (M/P) ratio on the grafting of acrylic acid onto wool fibers were studied at various monomer concentrations between $0.18 \mathrm{M}$ to $1.82 \mathrm{M}$ at a fixed concentration of initiator $\left(15 \times 10^{-3} \mathrm{M}\right)$, $\mathrm{H}_{2} \mathrm{SO}_{4}(0.75 \mathrm{M})$, Wool $(0.2 \mathrm{~g})$ for a reaction time of $6 \mathrm{~h}$ at five different temperatures between $35-55^{\circ} \mathrm{C}$. The percentage of grafting was found to increase steadily with monomer concentration and temperature simultaneously (Figure 1). This enhancement in percentage of grafting may be interpreted in terms of acrylic acid concentration and its reactivity. Increase in $\mathrm{M} / \mathrm{P}$ ratio increases monomer (AA) concentration at close proximity of the fiber backbone, where some of the acrylic acid molecules form a donor-acceptor complex, through interaction of their carboxyl functions with the pendent groups on wool backbone. Out of the uncomplexed monomers, those which are in the immediate vicinity of the reaction sites become acceptors of wool radicals resulting in chain initiation and thereafter they themselves become free-radical donors predominantly for uncomplexed monomers converted to stronger acceptors and neighbours than the remaining uncomplexed monomers situated a short distance away. These factors result in increase in the reactivity of the monomers thereby enhancing the percentage of grafting. Gaylord ${ }^{59}$ and Hebeish ${ }^{60}$ have also putforth a similar explanation for the enhancement of grafting at high monomer concentrations.

\section{ii) Effects of Initiator Concentration}

The effects of initiator concentration on grafting of acrylic acid onto wool fibers were studied at a number of initiator concentration from $0.00125 \mathrm{M}$ to $0.025 \mathrm{M}$, at a fixed weight of wool fibers $(0.2 \mathrm{~g})$, monomer concentration $(\mathrm{AA}=1.46 \mathrm{M})$, reaction time of $6 \mathrm{~h}$ and at five different temperatures $\left(35-55^{\circ} \mathrm{C}\right)$ (Figure 2 ). It was observed that the percentage of grafting increases with initiator concentration. The increse in percentage of grafting with initiator concentration may be ascribed to the increase in active sites on the backbone of wool fibers arising from the attack of diffused $\mathrm{V}^{+5}$ on the polymer matrix so that grafting also may occur in the interior region of the fiber. Since the grafted fibers get deteriorated at a higher concentration of initiator, further studies were carried out at the initiator concentration of $0.015 \mathrm{M}$. 


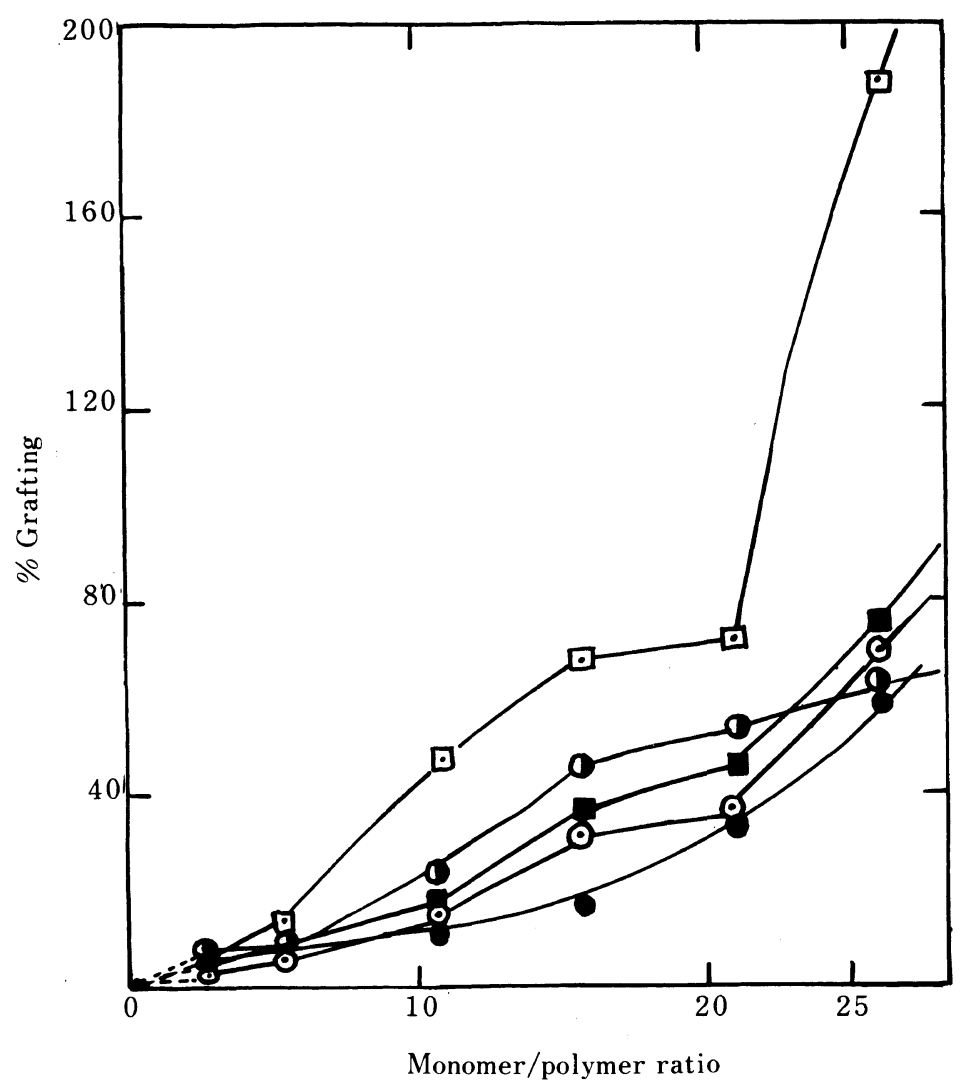

Figure 1. Variation in percentage of grafting at a fixed time. Effects of monomer/polymer ratio at different temperatures: wool $=0.2 \mathrm{~g} ;\left[\mathrm{V}^{+5}\right]=15 \times 10^{-3} \mathrm{M}$; time $=6 \mathrm{~h}$. (O) $T=35^{\circ} \mathrm{C} ;(\odot) T=40^{\circ} \mathrm{C} ;(\square) T=$ $45^{\circ} \mathrm{C}$; (@) $T=50^{\circ} \mathrm{C}$; () $T=55^{\circ} \mathrm{C}$.

\section{iii) Effects of Temperature}

Graft copolymerization of acrylic acid onto wool fibers has been studied at various temperatures $\left(35-55^{\circ} \mathrm{C}\right)$, with fixed concentration of $\mathrm{V}^{+5}\left(15 \times 10^{-3} \mathrm{M}\right)$, Wool $(0.2 \mathrm{~g})$ and reaction time of $6 \mathrm{~h}$ at different monomer concentrations $(\mathrm{AA}=0.18-1.82 \mathrm{M})$ (Figure 3 ). The percentage of grafting increases with both monomer concentration and temperature. The enhancement in percentage of grafting with rise in temperature may be attributed to (i) activation of the wool backbone and $\mathrm{V}(\mathrm{V})$, where facile oxidation of the former by the latter generates a large number of grafting sites at which monomer addition takes place and (ii) increase in temperature increases the rate of diffusion of AA into the fiber matrix, where grafting is also initiated at the interior region of the wool backbone. Samal and coworkers $^{61-63}$ made similar observations in the grafting of AM onto cellulose, Nylon-6 and silk fibers. Since the grafted fiber was deteriorated at temperature beyond $45^{\circ} \mathrm{C}$, further studies have been carried out at this temperature.

\section{iv) Effects of Solvent Composition}

The effects of various organic solvents such as acetone, acetic acid, methanol, formic acid, cyclohexanone and Pyridine on the extent of grafting have been studied at various solvent compositions of $(5: 95-50: 50 \mathrm{v} / \mathrm{v})$ at $45^{\circ} \mathrm{C}$ for fixed concentrations of AA $(1.46 \mathrm{M}), \mathrm{V}^{+5}$ $(0.015 \mathrm{M})$. Wool $(0.2 \mathrm{~g})$ for a reaction time of 


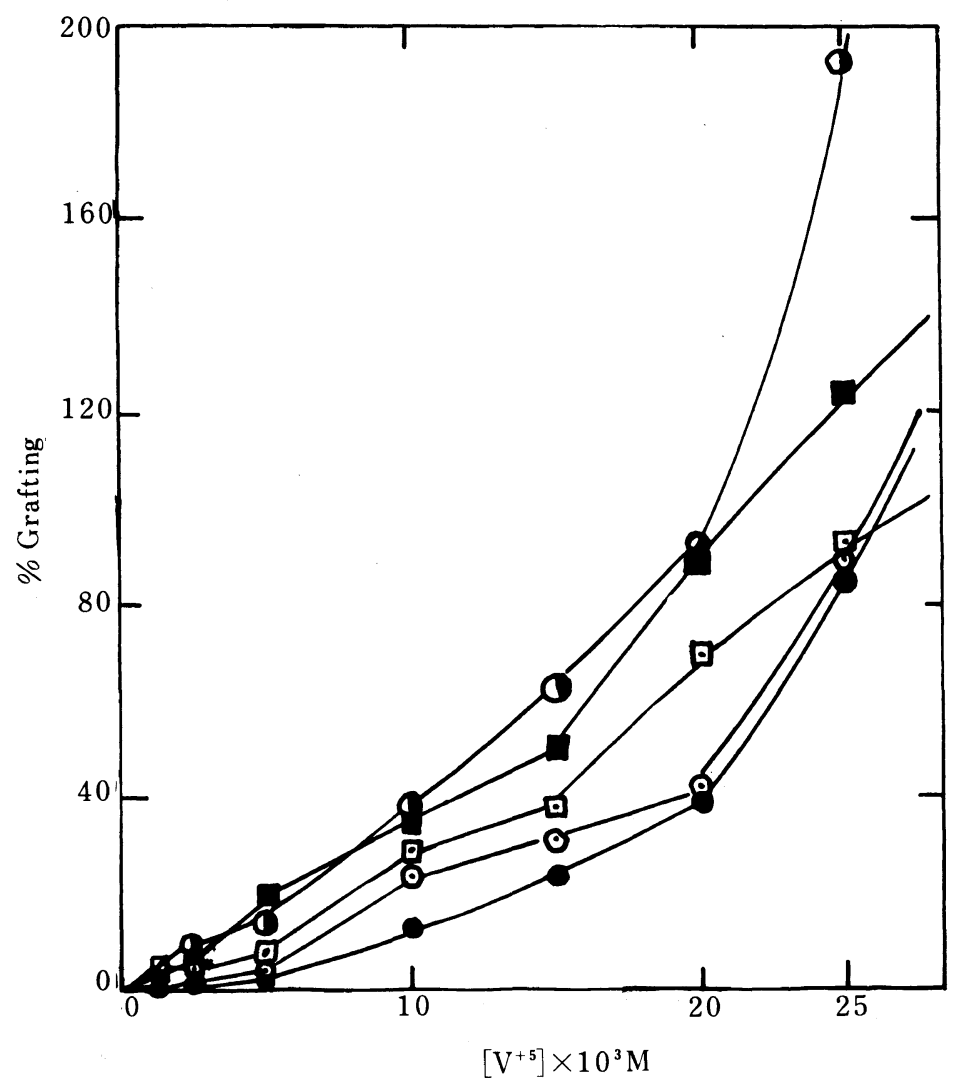

Figure 2. Variation in percentage of grafting at a fixed time. Effects of various $\left[\mathrm{V}^{+5}\right]$ at different temperatures: wool $=0.2 \mathrm{~g} ;[\mathrm{AA}]=1.46 \mathrm{M}$; time $=6 \mathrm{~h}$. (๑) $T=35^{\circ} \mathrm{C} ;(\odot) T=40^{\circ} \mathrm{C} ;(\odot) T=45^{\circ} \mathrm{C} ;(\square) T=$ $50^{\circ} \mathrm{C}$; (O) $T=55^{\circ} \mathrm{C}$.

$6 \mathrm{~h}$. The effects of these solvents under the cited reaction conditions on the extent of grafting are shown in Figure 4. From the figure, it is evident that in the presence of solvents like acetone upto $20 \%$ acetic acid and methanol upto $10 \%$, the percentage of grafting increases and then decreases. The presence of solvents like Pyridine and cyclohexanone progressively reduces the percentage of grafting, the extent being much higher in the presence of the former and at $50 \%$, it completely inhibits the grafting reaction. Further, it has been observed that for all proportions of formic acid, the percentage of grafting is higher than the control value, even though there is an initial increase upto $10 \%$ followed by decrease in the percentage of grafting. The increase in the percentage of grafting in the presence of formic acid may be attributed to (i) swelling of the fibers in its presence permits the monomer and the initiator to be diffused into the fiber matrix so that grafting is initiated both at the fiber surface and below the fiber surface, (ii) in addition, the swelling of the fiber also permits high accessibility of the surface of the wool fibers attack by primary radicals, creating more of free radical sites leading to graft initiation. The enhancement of percentage of grafting in the presence of the solvent like acetone, acetic acid and methanol at the cited compositions may be ascribed to the adequate amounts of solvent radicals contributing generation of greater number of grafting sites on the wool backbone which add a large number 


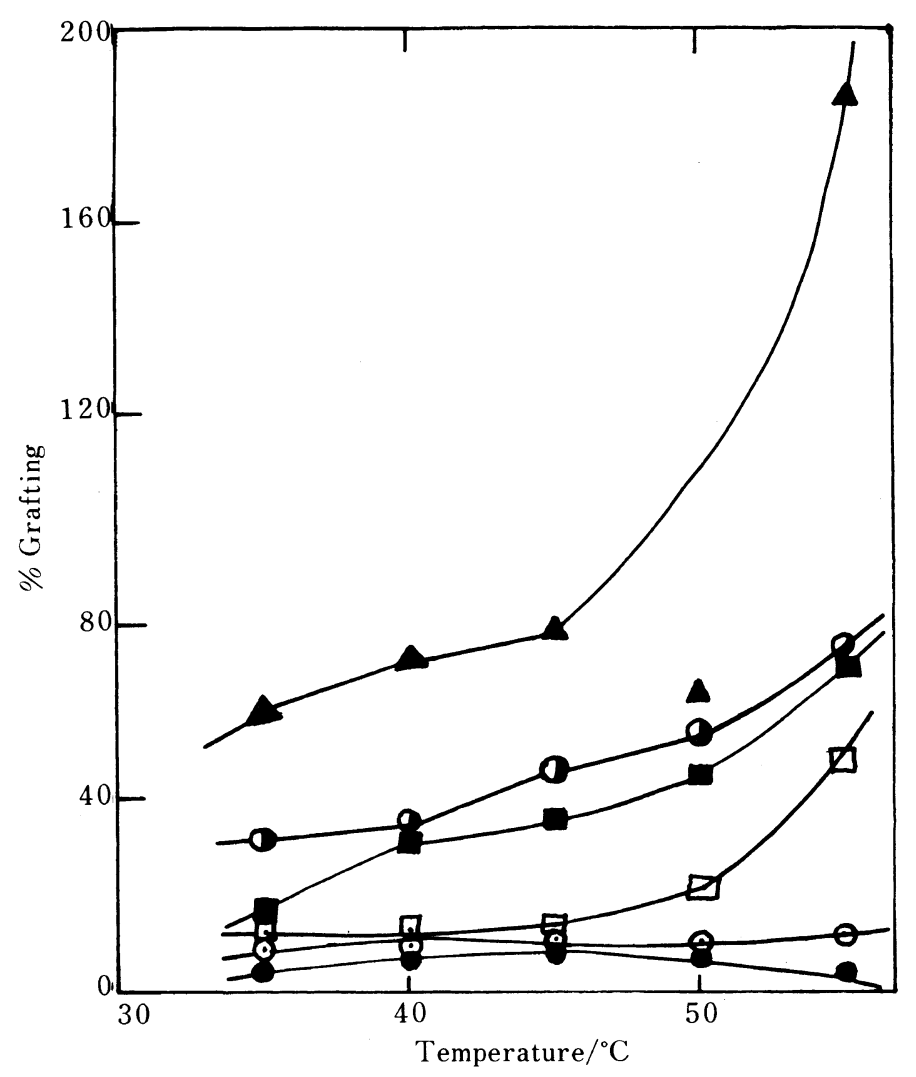

Figure 3. Variation in percentage of grafting at a fixed time. Effects of different temperatures at various $[\mathrm{AA}]$ : wool $\left.=0.2 \mathrm{~g} ; \mathrm{V}^{+5}\right]=15 \times 10^{-3} \mathrm{M} ;$ time $=6 \mathrm{~h}$. (๑) $[\mathrm{AA}]=0.18 \mathrm{M} ;(\odot)[\mathrm{AA}]=0.36 \mathrm{M} ;(\bullet)[\mathrm{AA}]=$ $0.73 \mathrm{M} ;(\mathbf{\square})[\mathrm{AA}]=1.09 \mathrm{M} ;(\mathbf{O})[\mathrm{AA}]=1.46 \mathrm{M} ;(\mathbf{\Delta})[\mathrm{AA}]=1.82 \mathrm{M}$.

of monomer molecules leading to high percentage of grafting. The retardation of the rate at higher percentage of these solvents and cyclohexanone may be due to (i) the chain transfer ability of these solvents leading to premature termination of the growing grafted chains, (ii) massive formation of homopolymers by excess solvent radicals upsets the grafting, (iii) shielding of the wool radicals by a solvent cage arising from interchain hydrogen bonding of the solvent molecules as a result of which monomer addition onto grafting sites is somewhat prevented. This is consistent with the view of Kern and coworkers ${ }^{64}$ and Palit and coworkers. ${ }^{65}$ The retardation and/or inhibition of grafting in the presence of Pyridine may be attributed to its oxidation to pyridine- $N$-oxide by $\mathrm{V}^{+5}$, which is capable of retarding and/or inhibiting radical polymerization depending on its concentration. The oxidation of pyridine to pyridine- $\mathrm{N}$-oxide ${ }^{66}$ and partial/complete inhibition or retardation of radical polymerization by $\mathrm{N}$-oxide are well recognized. ${ }^{67}$

\section{MECHANISM}

The mechanism of graft copolymerization onto wool fibers initiated by quinquivalent vanadium has been pictured as involving the initial complex formation of $\mathrm{V}(\mathrm{V})$ with either the pendent groups and/or the peptide linkage of the wool fibers. The intermediate complex subsequently disproportionates in an unimo- 


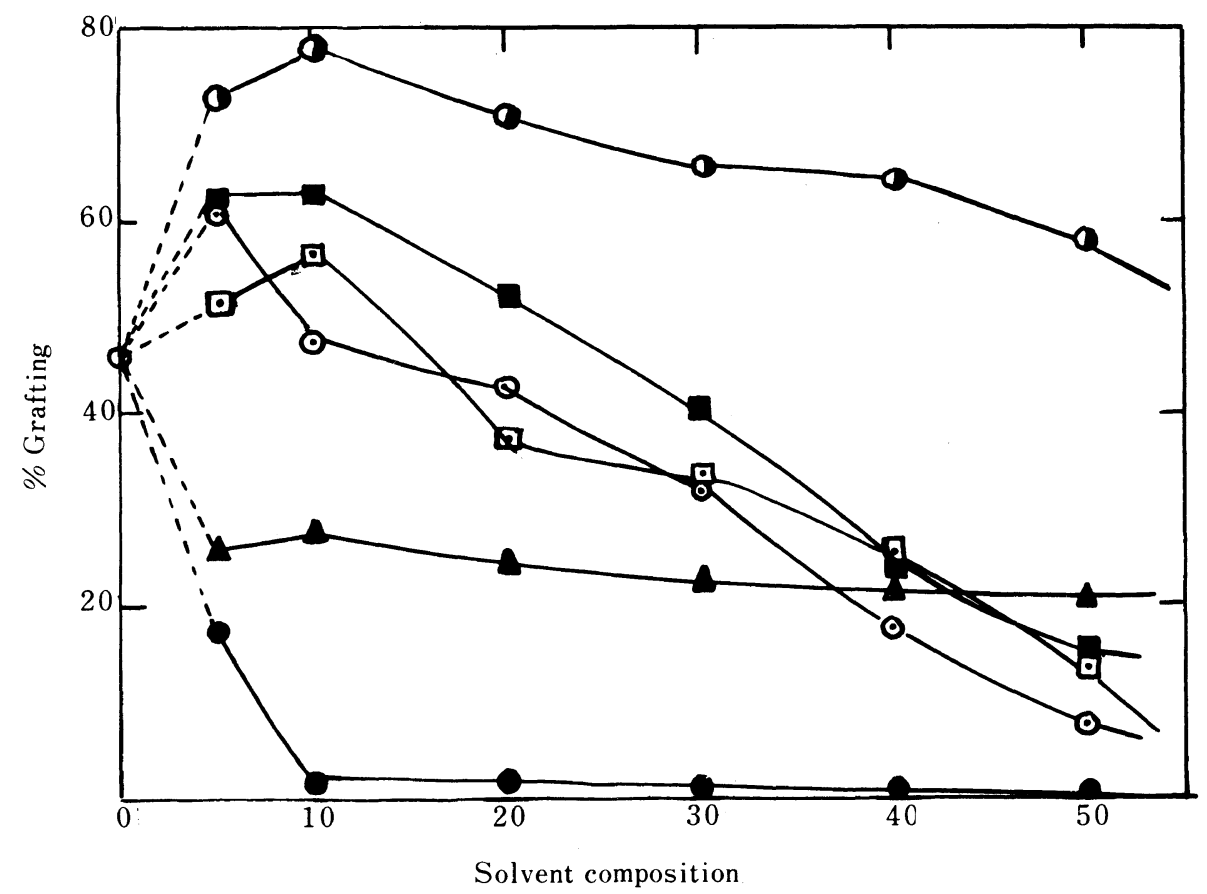

Figure 4. Variation in percentage of grafting at a fixed time. Effects of solvent composition: wool $=0.2 \mathrm{~g}$; $[\mathrm{AA}]=1.46 \mathrm{M} ;\left[\mathrm{V}^{+5}\right]=0.015 \mathrm{M} ;$ time $=6 \mathrm{~h} ;$ temp $=45^{\circ} \mathrm{C}$. $(\bigcirc)$ controlled value $=46.25 \% ;(\square)$ acetone; $(\square)$ acetic acid; $(\odot)$ methanol; $(\boldsymbol{O})$ formic acid; $(\odot)$ pyridine; $(\boldsymbol{\Delta})$ cyclohexanone.

lecular fashion to yield transient free radicals on the wool backbone. These free radicals initiate grafting. The termination of the growing polymer chains is caused by excess of metal ions. Oxidation of the transient free-radicals to products and dimerization of two macro wool radicals have also been suggested.

$$
\mathrm{W}-\mathrm{H}+\mathrm{V}(\mathrm{V}) \stackrel{K}{\rightleftharpoons} \text { complex }
$$

$$
\text { Complex } \stackrel{k_{\mathrm{d}}}{\longrightarrow} \mathrm{Wool}^{\bullet}+\mathrm{V}(\mathrm{IV})+\mathrm{H}^{+}
$$

Initiation:

(a) $\mathrm{W}^{\cdot}+\mathrm{M} \stackrel{k_{\mathrm{i}}}{\longrightarrow} \mathrm{W}-\mathrm{M}^{\cdot}(\mathrm{M}=$ monomer $)$

(b) $\mathrm{V}(\mathrm{V})+\mathrm{M} \stackrel{k^{\mathrm{i}}}{\longrightarrow} \mathrm{M}_{\mathrm{i}}$.

Propagation: (a) Wool $\longrightarrow \mathrm{M}^{-}+\mathrm{M} \stackrel{k_{\mathrm{p}}}{\longrightarrow}$ Wool $-\mathrm{M}_{2}^{\text {* }}$

$$
\text { Wool } \longrightarrow \mathrm{M}_{n-1}^{\cdot}+\mathrm{M} \longrightarrow \text { Wool }-\dot{\mathrm{M}}_{n}^{\cdot}
$$

(b) $\mathrm{M}_{\mathbf{i}}+\mathrm{M} \stackrel{k_{\mathrm{p}}^{\prime}}{\longrightarrow} \mathrm{M}_{2}^{\text {i }}$

$$
\dot{\mathrm{M}}_{m-1}^{\cdot}+\mathrm{M} \longrightarrow \mathrm{M}_{m}^{\dot{0}}
$$

Termination:

(a) Wool $-\mathrm{M}_{n}^{\cdot}+\mathrm{V}(\mathrm{V}) \stackrel{k_{\mathrm{t}}}{\longrightarrow}$ graft copolymer

(b) $\mathrm{M}_{m}^{\cdot}+\mathrm{V}(\mathrm{V}) \stackrel{k_{\mathrm{t}}^{\prime}}{\longrightarrow}$ homopolymer

(c) Wool $^{\circ}+\mathrm{V}(\mathrm{V}) \stackrel{k_{\mathrm{o}}}{\longrightarrow}$ oxidation product

(d) Wool $^{\bullet}+$ Wool $^{\cdot} \stackrel{k_{\mathrm{t}}}{\longrightarrow}$ dimeric product 
Applying the steady state approximation and assuming simple graft copolymerization, the rate of graft copolymerization was derived as follows:

$$
R_{\mathrm{p}}=\frac{K k_{\mathrm{p}} k_{\mathrm{i}} k_{\mathrm{r}}[\mathrm{M}]^{2}[\mathrm{Wool}-\mathrm{H}]}{k_{\mathrm{t}}\left(k_{\mathrm{i}}[\mathrm{M}]+k_{\mathrm{o}}[\mathrm{V}(\mathrm{V})]\right)}
$$

\section{Properties of the Grafts}

(1) Behaviour towards Acids and Alkalis. Acrylic acid grafted wool fibers showed higher affinity to alkalis in comparison to the ungrafted wool, probably due to the formation of corresponding sodium salts and to some extent due to the solubility of polyacrylic acid chain. Moderate resistance to the action of mineral acids at room temperature was observed. However at elevated temperatures and higher concentrations the grafted samples underwent deterioration and became brittle.

(2) Tensile strength. The tensile strength of the polyacrylic acid grafted wool fibers was determined from stiffness at the break following the method of Houque et al. ${ }^{68}$ and Samal et al. ${ }^{69}$ The stiffiness at the break was determined from the tenacity and elongation at the break using the relationship:

Stiffness at break $=\frac{\text { Tenacity at break }}{\text { Elongation at break }} \times 100$

The tenacity was expressed in $\mathrm{g} / \mathrm{denier}$. After conditioning the grafted samples, they were combed and fiber aggregates of uniform length were taken, weighed and their lengths determined. Tensile strength was determined by a "Dutrons" Tensile Tester, Brand-20 kfg capacity.

The results in Table II show that the tensile modulus of the wool fibers increases with the percentage of grafting upto $46.2 \%$ beyond which it decreases. The enhancement of tensile modulus upto the cited range may be attributed to entanglement of the grafted polyacrylic acid chains thus adding to the elastic behaviour of the fiber. The graft copolymer of percentage of grafting, $62.7 \%, 90.05 \%$, and
Table II. Effects of percentage of grafting on tensile properties of acrylic acid grafted wool fibers

\begin{tabular}{|c|c|c|c|c|}
\hline \multirow{2}{*}{ Samples } & \multirow{2}{*}{$\frac{\text { Grafting }}{\%}$} & \multirow{2}{*}{$\begin{array}{c}\begin{array}{c}\text { Elongation } \\
\text { at break }\end{array} \\
\frac{\text { B.L. } \%}{o}\end{array}$} & \multirow{2}{*}{$\begin{array}{l}\text { Tenacity } \\
\text { at break }\end{array}$} & \multirow{2}{*}{$\begin{array}{l}\text { Tensile } \\
\text { modulus }\end{array}$} \\
\hline & & & & \\
\hline Parent fiber & 0 & 1.48 & 2.75 & 185.8 \\
\hline \multirow[t]{7}{*}{ Wool-g-PAA } & 8.6 & 1.49 & 2.78 & 186.6 \\
\hline & 14.3 & 1.50 & 2.81 & 187.3 \\
\hline & 36.6 & 1.52 & 2.9 & 190.8 \\
\hline & 46.2 & 1.58 & 3.2 & 202.5 \\
\hline & 62.7 & 1.54 & 3.1 & 201.3 \\
\hline & 90.0 & 1.39 & 1.4 & 100.7 \\
\hline & 193.7 & 0.32 & 0.54 & 59.2 \\
\hline
\end{tabular}

$193.7 \%$ should have contributed more towards the elastic behaviour of the grafted sample but it showed a decrease in tensile modulus and the samples became more and more brittle. The probable explanation for this behaviour may be the reaction conditions under which they were prepared. These samples were prepared at high concentration of $\mathrm{V}^{+5}$, i.e., $15 \times$ $10^{-3} \mathrm{M}, 20.0 \times 10^{-3} \mathrm{M}$, and $25 \times 10^{-3} \mathrm{M}$, respectively. At these concentrations of $\mathrm{V}^{+5}$ in the reaction mixture, the backbone of the base wool fibers must undergo progressive oxidation and acid hydrolysis with increase in $\mathrm{V}^{+5}$ concentration. Due to this oxidative and hydrolytic degradation the graft copolymers $(62.7-193.7 \%$ ) exhibit decreasing tensile modulus.

(3) Dye Uptake. Sandocryl Golden yellow BGRL $300 \%$ dye was used for dyeing the fibers. The dye solution was prepared by adding $1 \mathrm{~g}$ of dyestuff to $100 \mathrm{ml}$ of hot water with constant stirring to obtain a clear solution. $1 \%$ shade was dyed on the material. The required amount $(10 \mathrm{ml})$ of the dye solution was placed in a breaker and to that $4 \mathrm{ml}$ of $1 \%$ ammonium sulphate solution were added. The material to liquor ratio was adjusted to $1: 40$ by adding the required amount of water. The $\mathrm{pH}$ of the dye solution was then maintained between 5 5.5 by adding dilute acetic acid dropwise. The concentration of the dye in this solution was 
Table III. Effect of percentage of grafting on dye uptake ability of parent wool and acrylic acid grafted wool fibers

Initial concentration of the dye solution $=13.23 \times 10^{-4}$.

\begin{tabular}{|c|c|c|c|c|c|}
\hline Sample No. & $\frac{\text { Grafting }}{\%}$ & $\begin{array}{l}\text { Absorb- } \\
\text { ance } \\
\text { (O.D) }\end{array}$ & $\begin{array}{l}\text { Concentration } \\
\text { of the dye } \\
\text { after dyeing }\end{array}$ & $\begin{array}{l}\text { Dye uptake in } g \text { of } \\
\text { the dye } g^{-1} \text { of } \\
\text { the fiber }\end{array}$ & $\begin{array}{c}\text { Dye uptake in } \mathrm{g} \text { of } \\
\text { the dye } \mathrm{kg}^{-1} \text { of } \\
\text { the fiber }\end{array}$ \\
\hline Raw wool & - & 0.155 & $4.75 \times 10^{-4}$ & $8.48 \times 10^{-4}$ & $8.48 \times 10^{-1}$ \\
\hline Wool- $g$-PAA & $50 \%$ & 0.109 & $3.34 \times 10^{-4}$ & $9.89 \times 10^{-4}$ & $9.89 \times 10^{-1}$ \\
\hline Wool-g-PAA-Na-salt & $\begin{array}{l}\text { After } 50 \% \text { dyeing } \\
\text { it was converted } \\
\text { to } \mathrm{Na} \text { salt }\end{array}$ & 0.600 & $1.84 \times 10^{-4}$ & $11.39 \times 10^{-4}$ & $11.39 \times 10^{-1}$ \\
\hline
\end{tabular}

Table IV. Water retention of the Wool-g-PAA samples at various percentages of grafting

\begin{tabular}{ccc}
\hline Samples & $\begin{array}{c}\text { Percentage of } \\
\text { grafting }\end{array}$ & $\begin{array}{c}\text { Water retention } \\
\text { in } \mathrm{g} \mathrm{g}^{-1}\end{array}$ \\
\hline Parent fiber & 0 & 3.0 \\
Wool-g-PAA & 8.6 & 6.2 \\
& 14.3 & 8.4 \\
& 36.6 & 16.5 \\
& 46.2 & 20.8 \\
& 62.7 & 28.9 \\
\hline
\end{tabular}

measured by a spectrophotometer at $750 \mathrm{~nm}$. The sample was prewetted and dipped into the dye solution. The breaker was then kept over a hot plate and the temperature was raised to $80^{\circ} \mathrm{C}$ by $5^{\circ} \mathrm{C} \mathrm{min}^{-1}$, then from $80-100^{\circ} \mathrm{C}$ the temperature was raised slowly by $1{ }^{\circ} \mathrm{C} \mathrm{min}^{-1}$. Dyeing was carried out at $100^{\circ} \mathrm{C}$ for $45 \mathrm{~min}$ till all the colour was gone from the fiber. After dyeing, the material was rinsed in cold water and air dried. The initial concentration of the dye solution and that remaining after dyeing were determined by the following formula

$$
C=\frac{\text { O.D. }}{a_{\lambda}}
$$

where

$$
\text { O.D. = optical density }
$$$$
a=\text { constant }(0.4343 k)
$$$$
\lambda=750 \mathrm{~nm} \text {. }
$$

The resulting dye uptake ability of the fibers was determined by measuring the difference in the initial and remaining concentrations of the dye solution and is shown in Table III. The results showed that grafting of acrylic acid increases the dye uptake ability of wool fibers.

(4) Absorption of Water and Water Vapours (Water Retention). The extent of absorption of water and water vapours of both the grafted and virgin wool fibers was determined by measurement of water retention of the samples following the method of Rånnby et al. ${ }^{70}$ with slight modification. The water retention increased with the percentage of grafting. One gram of both virgin and grafted fibers was separately immersed in $100 \mathrm{ml}$ of distilled water for $12 \mathrm{~h}$. The contents were then filtered through a sintered glass filter and sucked at $700 \mathrm{mmHg}$ pressure. The volume of the filtrate was measured and the water retention equal to the amount of water absorbed was calculated as $g$ of water per $g$ of dry material.

Acknowledgement. The authors are very thankful to Prof. Y. Ikada, Research Centre for Medical Polymers and Biomaterials, Kyoto University, Japan for his continuous inspiration and valuable suggestions.

The financial support by C.S.I.R., India, New Delhi is greatefully acknowledged.

\section{REFERENCES}

1. P. Alexander and R. F. Hudson, "Wool. 'Its Chemistry and Physics," Reinhold, New York, N. Y., 1954, p 334 FF. 
2. N. H. Koenig, U. S. Patent 2993748 (July 25, 1961).

3. N. H. Koenig, Textile Res., J., 32, 117 (1962).

4. H. Fraenkel-Conrat, M. Cooper, and H. S. Olcott, J. Am. Chem. Soc., 67, 314 (1945).

5. N. H. Koenig, paper presented at the Technical Wool Conference San Francisco, California, May 13, 1964 [Textile Res. J., 35, 708 (1965)].

6. R. E. Whitfield, L. A. Miller, and W. L. Wasley, J. Appl. Polym. Sci., 8, 1607 (1964).

7. W. Fong, R. E. Whitfield, L. A. Miller, and A. H. Brown, Am. Dyestuff. Reptr., 51, 325 (1962).

8. R. E. Whitfield, L. A. Miller, and W. L. Wasley, Textile Res. J., 31, 704 (1961).

9. R. E. Whitfield, L. A. Miller, and W. L. Wasley, Textile Res. J., 32, 473 (1962).

10. R. E. Whitfield, L. A. Miller, and W. L. Wasley, Textile Res. J., 33, 440 (1963).

11. L. A. Valentine, J. Text. Inst., 46, 270 (1965).

12. H. Ishibashi and $\mathbf{M}$. Oku, Proceedings of International Wool and Textile Research Conference, Paris, 1965, Section III, p 385.

13. M. Negishi, K. Arai, and S. Okada, J. Appl. Polym. Sci., 11, 115 (1967).

14. J. L. Willams and V. Stannett, Text. Res. J., 38, 000 (1968).

15. H. L. Needles and W. L. Wasley, Text. Res. J., 39, 97 (1969).

16. I. C. Watt, J. Macromol. Sci. Rev. Macromol. Chem., C5, 176 (1970).

17. H. L. Needles, L. J. Sarfield, and D. M. Dawhaniuk, Text. Res. J., 42, 558 (1972).

18. K. Arai, M. Negishi, S. Komine, and K. Takada, Appl. Polym. Symp., 18, 545 (1971).

19. H. L. Needles and L. J. Sarfield, Appl. Polym. Symp., 18, 569 (1971).

20. A. J. Makinnon, J. Appl. Polym. Sci., 14, 3033 (1970).

21. D. S. Varma and R. K. Sarkar, Text. Res. J., 41, 610 (1971).

22. A. Hebish and A. Bendak, Teintex, 10, 719 (1971).

23. A. Kantouch, A. Hebeish, and A. Bendak, Eur. Polym. J., 7, 153 (1971).

24. W. S. Simpson, Appl. Polym. Symp., 18, 967 (1971).

25. A. Kantouch, S. Abdel-Fattah, and A. Hebeish, Polym. J., 3, 375 (1972).

26. A. Hebeish, A. Bendak, and S. Abdel-Fattah, Angew. Makromol. Chem., 37, 11 (1974).

27. S. Abdel-Fattah, A. Kantouch, and A. Hebeish, Angew. Makromol. Chem., 43, 11 (1975).

28. A. Hebeish, S. H. Abdel-Fattah, and M. H. El. Rafie, J. Appl. Polym. Sci., 20, 3449 (1976).

29. N. C. Pati, S. Lenka, and P. L. Nayak, Die Anget. Makromol. Chemie, 71, 189 (1978).

30. B. N. Mishra, I. Kaur, and R. K. Sharma, Polym. Bull. (Berlin), 4, 635 (1981).

31. P. L. Nayak, G. Sahu, and S. Samal, J. Macromol. Sci. Chem., A16, 1309 (1981).
32. M. K. Mishra and B. L. Sar, J. Macromol. Sci. Chem., A18, 575 (1982).

33. S. Samal, G. Sahu, and P. L. Nayak, J. Macromol. Sci. Chem., A20, 153 (1983).

34. J. S. Shukla, G. K. Sharma, R. K. Tewari, and S. K. Shukla, J. Macromol. Sci. Chem., A21, 225 (1984).

35. J. S. Shukla and G. K. Sharma, Indian J. Chem. Sect. $A$, A24, 467 (1985).

36. J. S. Kim and W. S. Ha, Han'guk Somyu Konghakhoechi, 23, 472 (1986).

37. J. S. Shukla, S. C. Tewari, and G. K. Sharma, J. Appl. Polym. Sci., 34, 191 (1987).

38. B. O. Bateup, H. D. Feldtman, and B. E. FleischFresser, J. Text. Inst., 72, 34 (1981).

39. A. Kantouch, A. Bendak, and M. Sadek, Text. Res. J., 48, 619 (1978).

40. W. J. Thorsen, Ozone. Sci. Eng., 1, 219 (1979).

41. J. D. Garcia, P. Erra, A. M. Dela, M. R. Julia, A. Barella, and T. Shaw, J. Text. Inst., 71, 165 (1980).

42. N. H. Koenig and M. Friedman, U. S. Patent Applied 57858, 15 February 1980, Applied 16 July 1979, p 14.

43. R. J. Cook and E. D. Rivett, Text. Res. J., 57, 596 (1981).

44. R. L. Greaves, P. H. Roche, and M. A. White, Text. Res. J., 5, 681 (1981).

45. E. E. Ney, R. Peake, and N. Regos, Colourage, 28, 31 (1981).

46. K. Byrne, Eur. Patent Applied Ep. 209323, 21 January 1987, GB Applied 85/17,740, 13 July 1985, p 11.

47. M. A. Parry, Br. Patent GB Applied 2, 174424, 05 November 1986, GB Applied 85/10,038, 19 April 1985, p 6 .

48. B. H. Jang, S. W. Nam, and M. Sakamoto, Han'guk Somyu Konghakhoechi, 24, 68 (1987).

49. P. Erra, M. R. Julia, P. Burgues, and M. R. Infante, Tenside, Surfactante, Deterg., 25, 275 (1988).

50. P. Erra, M. R. Julia, M. R. Infante, M. L. Coderch, and J. J. G. Dominguez, J. Soc. Dyers Colour., 104, 93 (1988).

51. A. Szpala, Eur. Patent Applied Ep. 260017, 16 March 1988, GB Applied 86/21,171, 02 September 1986, p 16.

52. R. K. Samal and G. Giri, J. Macromol. Sci. Rev. Macromol. Chem. (communicated).

53. W. A. Waters and J. S. Littler, "Oxidation in Organic Chemistry," Part-A, K. B. Wiberg, Ed., Academic Press Inc., New York, 1965, pp 186-240.

54. Y. Ikada, Y. Nishizaki, Y. Uyama, T. Kawahara, and I. Sakurada, J. Polym. Sci., Polym. Chem. Ed., 14, 2251 (1976).

55. S. F. Sadova, M. V. Korchagin, and E. O. Kazakova, Otkrytiya, Izobret., Prom. Obraztsy. Tovarnye Znaki, 54, 107 (1977).

56. P. L. Nayak, S. Lenka, and N. C. Pati, Angew. Makromol. Chem., 71, 189 (1978). 
57. P. L. Nayak, S. Lenka, and N. C. Pati, J. Appl. Polym. Sci., 22, 3301 (1978).

58. G. Wu, D. Lu, P. Zhou, J. He, and W. Tao, Jilin Daxue Ziran Kexue Xuebao, No. 2, 77 (1983).

59. N. G. Gaylord, J. Polym. Sci., C, 37, 153 (1972).

60. A. Hebeish, M. I. Khalil, and M. H. El-Rafie, Angew. Makromol. Chem., 37, 149 (1979).

61. R. K. Samal, P. K. Sahoo, and H. S. Samantaray, J. Appl. Polym. Sci., 32, 5693 (1986).

62. R. K. Samal, P. L. Nayak, and M. C. Nayak, Die. Angew. Macromol. Chem., 80, 95 (1979).

63. R. K. Samal, S. C. Satrusallya, B. L. Nayak, and C. N. Nanda, J. Appl. Polym. Sci., 28, 1311 (1983).

64. W. Kern, R. Schulz, G. Renner, and A. Henglein,
Makromol. Chem., 12, 20 (1954).

65. S. R. Palit and R. S. Konar, J. Ind. Chem. Soc., 38, 481 (1961).

66. R. J. Kennedy and A. M. Stock, J. Org. Chem., 25, 1901 (1970).

67. M. Kinoshita, Y. Miura, and S. Masuda, Makromol. Chem., 160, 243 (1972).

68. M. M. Haque and M. D. Habibuddowla, Bangladesh J. Sci. Ind. Res., 15(1-4), 64 (1980).

69. R. K. Samal, H. S. Samantaray, and R. N. Samal, Polym. J., 18, 471 (1986).

. B. Ranby and L. Gadda, Am. Chem. Soc. Symp. Ser., 187, 33 (1982). 